\title{
Oração de agradecimento
}

\author{
D. José Gaspar de Afonseca e Silva
}

Recebendo-me nesta casa, de modo tão solene quão carinhoso, mostra-se a Universidade de São Paulo pródiga com os meus merecimentos e justa para com a Santa Igreja Católica. Por mais que se avantaje na vida do espírito, deve o homem - pequenino e efêmero - guardar sempre consigo a medida humilde de seu tamanho, não lhe venha a soberba convencê-lo de que é maior do que a sua porporção natural. Às vezes, porém, toca-lhe a ventura de incarnar uma grande aspiração popular, a glória de conduzir para o triunfo uma nobre idéia ou a graça de representar uma doutrina vital.

Bispo da Santa Igreja, por mercê de Deus, dou-me bem com a vossa fidalga e cativante companhia e recebo comovido esta homenagem. Na tristeza destes dias em que assistimos ás passageiras vitórias da fôrça sobre o direito, da matéria sobre o espírito, a Universidade de São Paulo a si mesma se honra, tributando, na pessôa do Arcebispo, o seu preito de veneração à Igreja Católica, criadora das primeiras instituições deste gênero e a que melhor lhe definiu o papel na cultura geral de um povo. Bem poucas, dentre as mais famosas e antigas, as que não tiveram sua certidão de nascimento escritas pela mão soberana dos Papas, guiados nesta empresa por um pensamento de unificação espiritual.

De fato: a inteligência não é dispersiva mas unificadora. Versando sobre todos os entes - pois o ser e a inteli- 
gibilidade se comensuram - não é, todavia, sua finalidade isolar-se numa parcela do universo, por mais ilimitados que pareçam aos olhos pesquisadores os horizontes daquele minúsculo desvão. Especializando-se, a razão caminha para a universalidade dos conhecimentos, os quais encontram em Deus a própria síntese do saber humano.

Ora, o que se observa nos campos interiores do espírito, deve traduzir-se, na esquematização dos estudos, numa fórma concreta, numa organização escolar que faça convergir a programação dos conhecimentos para a unidade da ciência.

Como a nossa inteligência apreende sucessivamente os aspetos das coisas, e das mais simples se eleva até as mais complexas, os estudos universitários, que abrangem a pluriformidade dos conhecimentos, devem conduzir o homem para o ápice de toda a ciência: para Deus. Orientam a razão, por que se não perca sòzinha, nas pesquisas mais afastadas; elevam o espírito, mostrando-lhe as rotas mestras do pensamento; asseguram a justa distância para o exato julgamento das coisas, e apontam segura e firmemente ao homem o destino duradouro a que aspiram suas faculdades superiores.

Para tanto, uma Universidade bem estruturada fundamenta todos os seus cursos num sólido currículo ginasiai e num adequado preparo filosófico - elementos indispensaveis para toda formação científica digna deste nome.

Entendido como o quer a Igreja, o papel de uma Universidade, na cultura geral de um povo, tem algo de extraordinário e sobrenatural: unifica o pensamento da nação, dá-lhe coesão política, disciplina de costumes, continuidade educacional, constância de esforços, garantindo-lhe a liberdade, assegurando-lhe o progresso e a justiça - pois é bem sabido que as desordens, quando estalam sanguinolentas nas ruas e nas praças, já antes convulsionavam os cérebros e separavam as inteligências. Ainda mais: todo estudo universitário, feito com orientação segura e sincero empenho, 
leva gloriosamente todo o homem para Deus - autor de nossa faculdade intelectiva, fonte de todo o saber, princípio de todas as ciências, para o qual, senhores, convergimos todos, como termo que é das nossas aspirações, juiz dos nossos atos e recompensa única de nossa vida.

Dentro desta casa, quanto sois felizes, senhores professores e caros alunos, por devotardes vossa existência uns, vossa mocidade outros, à procura dos bens do espírito. Estes, na ordem cristã, formam grande parte daquele "optimum hominis" que Santo Agostinho preconizava para um de nós.

Que valem os deleites corporais, as honrarias, as glórias? A ninguem satisfazem, porque nenhuma atividade inferior pode saciar o coração humano. A vida dos sentidos põe-nos apenas ao nivel dos irracionais, que tambem a exercem. Só os bens do espírito nos libertam: "veritas liberabit vos" São em nós lembranças do infinito. Alam-nos o coração para as sublimes ascensões. Talvez cogitando nesta verdade é que Flaubert escreveu aquele seu pensamento ungido de piedade e de tristeza: "Creio que se olhássemos sempre para o céu, acabariamos possuindo asas" Desgraçadamente, senhores, não .o fazemos o quanto era para desejar.

Buscando os bens espirituais e sobrenaturais, somos ainda nobremente ditosos, por cultivarmos o maravilhoso dom da razão que Deus nos outorgou, a qual pode "intentionaliter fieri omnia" Pequeninos, somos menos que um átomo, se comparamos as dimensões do nosso corpo com as enormes massas dos globos sidéreos que girovagam pelo universo. Entretanto, mercê da aptidão intelectiva, somos capazes dr a todos eles abranger e dominar, pois que podemos conhecê-los todos. A inteligência humana é devéras a admiravel miniatura da universal inteligência de Deus, encerrada no estreito âmbito da nossa personalidade criada.

PAscal, que lapidou seus geniais pensamentos em formosas frases, exprimiu tais verdades nestas linhas tão co- 
nhecidas: "O homem é apenas um caniço, o mais fragil da natureza; mas é um caniço que pensa. Não há mister sie arme todo o universo para o esmagar: um vapor, uma gota d'agua é o bastante para matá-lo. Mas quando o universo o esmagasse, o homem seria ainda mais nobre de quem o mata, porquanto sabe o homem que morre e ignora o universo a vantagem que sobre ele tem. Toda a nossa dignidade, portanto, está no pensamento. Trabalhemos, pois, por pensar bem"

Sim: toda a nossa dignidade consiste no pensar. Mas é preciso pensar bem, e a isto, no ideal eclesiástico, se destinam as Universidades.

Nascida ontem apenas, reunindo já a fina flor das nossas inteligências, marcha a Universidade de São Paulo para um futuro promissor. Guardai-a, senhores, dentro da nossa formação histórica, das tradicionais tendências do nosso povo, orientando-a pelos princípios da nossa fé, abrigando-a dos maléficos ventos que para cá pudessem carrear os germes de corrupção, que lá fóra dissolvem os povos e infelicitam as nações. Assim, no âmbito dos vossos estudos, no termo das vossas pesquisas, podereis nobremente, livremente, dobrar os joelhos e adorar o Criador de todas as coisas, porque na vossa intelectual ascensão não subiu convosco o orgulho humano, terrivel inimigo da nobreza d'alma. Para além dos horizontes atingidos pela inteligência criada, todo estudo se transmuda em oração, e ditosos os que sabem rezá-la!

Como Arcebispo e vosso amigo, seja-me permitido, senhores professores, protestar-vos minha imensa simpatia e ofertar-vos as minhas preces que exoram de Deus todas as bênçãos para o vosso magistério. Professor tambem o fui, se bem que dos mais obscuros, apaixonado, não obstante, pela minha cátedra. Sei quão temerosas são essas responsabilidades. Vós bem de perto as conheceis, e melhor do que eu sabeis que as violências mais criminosas não são os inominaveis abusos da força bruta que esmaga povos livres 
* escraviza nações. 0 pior despotismo bem pode ser o da cátedra, quando sorrateiramente inocula dos cérebros desprevenidos teorias deletérias, ou com arte súbdola mina o patrimônio das nossas crenças.

Infelizmente, ou não, tem o êrro sobre a verdade a vantagem do figurino. Sabe vestir-se mais vistosamente, trajar terminologia nova, garrir-se de hipóteses ou impressionar com leorias nascidas em momentos de excessiva imaginação. A verdade, ao contrário, contenta-se com a própria formosura natural, tão simples e encantadora que só por si basta para conquistar toda inteligência ponderada.

Porque estais imunes de semelhante fascinação, senhores professores, e lecionais escudados em vossa conciência cristã, recebei as minhas saudações e os votos por que seja a vossa cátedra contribuição notável para a construção do Brasil. Fiéis ao vosso ideal, formareis as inteligèncias brasileiras orientando-as para a verdade, o que será sempre vizinhá-las de Deus. Mereceis por isto a gratidão do país. Aceitai tambem a minha, obscura mas afetuosa, que deixo nas mãos honradas do Exmo. Senhor Reitor da Universidade de São Paulo e do mui digno Diretor da Faculdade de Direito, cujas palavras agradeço de coração.

E para vós, juventude caríssima da Universidade de São Paulo, seja o meu reconhecimento uma doce esperança depositada no vosso coração. Alvoreceis para a vida em dias tão tristes para o mundo! Se vos minguasse a fé e vos faltasse a coragem, recuar seria a única atitude da vossa geração, receiosa de receber um espólio suspeito, que vos querem legar estes primeiros anos do século vinte. Não vos intimideis, porém. Os grandes sofrimentos dos povos trazem latentes muitas energias construtivas. Em geral, nas horas trágicas é que se revela a plenitude das forças humanas. Golpeai o bronze com arminho e ele quedará mudo e insensivel; basta, no entanto, que o firais com o martelo, e ele ressoará, e sua voz ganhará dominadora os ares, as ci- 
dades, os vales, as serras. A conciência cristã sofre hoje rudes assaltos; nossa educação mal suporta a frieza impudente co mque se canonizam absurdos no govêrno dos povos. E tudo parece que se apresenta ao espírito com tintas de um ocaso para a civilização.

Pouco importa: amemos a Deus e procuremos a verdade e cultuemos a justiça. Consideremos a Santa Igreja. Mesmo aos não católicos, pode ela ensinar, com seus dois milênios de existência. O despotismo dos cesares e as explosões das anarquias; as ameaças dos poderosos que estão a repetir monòtonamente, de século em século, a mesma sediça linguagem sem saberem como variá-la, têm funestado a Igreja e arrancado do seu materno regaço famílias e nações. Jamais, porém, obtiveram a renúncia de um principio, o repúdio de uma verdade, a alienação de um direito da conciência, nem a abdicação da mínima parcela de liberdade da alma! Se o houvesse feito, ter-se-ia ela aparceirado com o êrro, em momentâneo gôzo do poder e prevaricado contra o Espírito. E são pecados estes, para os quais não h̀a remissão no tribunal de Deus.

Não vos assuste, pois, o estrépito da fôrça, nem as truculências da brutalidade. Já o disse Cristo infalivel: "Quem fere com a espada, com a espada será ferido" E' verdade dos Santos Evangelhos, clara e evidente para quem queira ter a paciência de esperar. O espírito vence e triunfa sempre, na batalha derradeira.

Contudo, para que nesta admiravel terra que o Senhor nos deu por Pátria cresça um povo forte, calmo, disciplinado, religioso, paladino do direito, da justiça e da liberdade, é preciso que cada geração de moços se prepare e se aprimore para a missão que lhe reserva o futuro. Atentai na frase admoestadora de São JoÃo: "Major est qui in vobis est quam qui in mundo" Há em vós algo maior do que todo o resto do mundo. Sois vós mesmos, sustentados pela graça divina; é a vosas própria alma, a vossa conciência, a vossa razão, o vosso coração. 
Valorizai-vos, pois, individualmente, para tornar a mocidade brasileira cada vez mais digna do Brasil.

O caminho para esta ascensão de vossa primavera, traçou-o SANTo Agústinho em três princípios apenas, que confio à juventude universitária de São Paulo. Guardai-os:

"NOLI FORAS IRE" Não sáias fóra de ti mesmo, buscando no exterior o prazer, o pecado, o vício, pois af́ te perdes e aniquilas. Não queiras abandonar-te.

"IN TEIPSUM REDI", Volta para dentro do teu ser, para o interior da tua conciência, do teu coração, da tua inteligência, e aí constróe, com a graça de Deus, o teu caráter, desde já tão promissor de esperanças. Assim concentrado, por este caminho do teu próprio valor, santificado pelo auxílio divino, muito poderás crescer.

“TRANSCENDE TE IPSUM" Supera-te a ti mesmo. Torna-te maior do que o teu primitivo tamanho. Agigantate. Sublima-te. Santifica-te. "Transcende te ipsum"

Agradecendo aos queridos universitários paulistas as saudações que me dirigiram pelos lábios de um dos seus mais distintos colegas, aquí deixo confiado, a cada uma das vossas generosas conciências, o meu brado de Arcebispo, de amigo e de brasileiro:

MOCIDADE DE SÃO PAULO, PELA GLORIA DE DEUS E POR AMOR DO BRASIL E DO SEU POVO,

SUPERA-TE A TI MESMA, "Transcende te ipsam", TORNA-TE CADA VEZ MAIOR E MELHOR! 